\title{
Successful Percutaneous Treatment of Coronary Artery Ectasia with Drug-Eluting Stent
}

\author{
Bhupesh Rajanikant Shah', Ashok S. Thakkar² \\ ${ }^{1}$ Department of Cardiology, NHL Municipal Medical College, Ahmedabad, India \\ ${ }^{2}$ Department of Clinical Trials, Sahajanand Medical Technologies Pvt. Ltd., Surat, India \\ Email: shahbhupesh@hotmail.com
}

Received 7 September 2014; revised 6 October 2014; accepted 5 November 2014

Copyright (C) 2014 by authors and Scientific Research Publishing Inc.

This work is licensed under the Creative Commons Attribution International License (CC BY). http://creativecommons.org/licenses/by/4.0/

(c) (i) Open Access

\begin{abstract}
Coronary artery ectasia is well-known but relatively uncommon finding with prevalence ranging from $\mathbf{1 . 2 \%}$ to $5.3 \%$. Coronary artery ectasia has been associated with atherosclerosis in approximately half of the cases. Here, we are presenting a case of male patient who experienced myocardial infarction and was diagnosed with coronary artery ectasia in proximal-mid junction of left anterior descending artery with stenotic lesion. The patient was successfully treated with percutaneous transluminal coronary angioplasty.
\end{abstract}

\section{Keywords}

Coronary Artery Ectasia, Drug Eluting Stent, Percutaneous Coronary Intervention

\section{Introduction}

Coronary artery ectasia (CAE) is commonly defined as an inappropriate dilation of the coronary arteries exceeding the largest diameter of an adjacent normal vessel more than 1.5 fold [1]. It is well-known but relatively uncommon finding with an estimated prevalence ranging from 1.2\% to 5.3\% [1]-[3]. Diffuse dilation of the coronary artery is called ectasia whereas focal dilation refers to coronary aneurysm [4]. The clinical significance of CAE is not fully clarified. There is no typical symptom that could be associated with CAE [5]. As in majority of the cases (more than 50\% cases), the CAE has been associated with stenotic lesions, the clinical presentation and long-term cardiac complications are mostly associated with the severity of the stenotic coronary lesions [1] [3]. Here, we are presenting a case of a male patient who experienced myocardial infarction and was diagnosed with CAE in proximal-mid junction of left anterior descending artery (LAD) with stenotic lesion. The patient was 
successfully treated with percutaneous transluminal coronary angioplasty (PTCA).

\section{Case Report}

A 48-year-old male patient, known case of diabetes mellitus (type-II), presented with the chief complaints of sudden onset of severe sub-sternal chest pain with radiation to the left arm and jaw for 8 to 10 hours along with nausea, vomiting and dyspnea. The patient was thrombolysed with streptokinase in view of acute anterior wall myocardial infarction. The patient was referred to our clinic for further evaluation.

The echocardiographic evaluation demonstrated ejection fraction less than 30\%. Coronary angiogram (CAG) revealed single vessel disease: 70\% occlusion in proximal LAD, 90\% occlusion in mid-LAD, ectasia in proximalmid junction of LAD with normal left coronary circumflex artery (LCX), right coronary artery (RCA) and left main coronary artery (LMCA) (Figure 1). We decided to perform PTCA with stent implantation into LAD.

Primary PTCA of LAD was initiated using a 6F EBU guiding catheter and 0.014 BMW PTCA guidewire through right radial approach. A drug-eluting stent, $2.5 \times 32 \mathrm{~mm}$ SUPRALIMUS-CORE (Sahajanand Medical Technologies Pvt. Ltd., Surat, India), was deployed in proximal-mid LAD. Post-dilatation was carried out using $2.75 \times 10 \mathrm{~mm}$ Maverick balloon at 10 atmosphere pressure. Check-angiogram showed well-placed stent in proximal-mid LAD (Figure 2). The patient tolerated procedure well.

The patient was discharged from the hospital after two days of the procedure. He was prescribed dual antiplatelet treatment (aspirin-300 mg and clopidogrel-150 mg), statin, $\beta$-blocker and angiotensin converting enzyme inhibitor.

\section{Discussion}

CAE is a rare but well-reported finding during diagnostic coronary angiography. RCA is the most commonly affected artery and LMCA is the least frequently affected whereas involvement of LAD and LCX is variable [6]. CAE has been classified in several ways. The classification system suggested by Markis et al. [3] has been widely used which is based upon the number and diffuseness of the involved coronary vessel. The classification has been shown in Table 1. In our case, patient had type-4 ectasia in LAD.

The most common etiology is atherosclerosis, responsible for more than $50 \%$ cases in adults [1] [7] [8]. Other causes include coronary artery revascularization procedures-iatrogenic complication, vasculitides (i.e. Takayasu arthritis, Kawasaki disease), congenital malformations, chest traumas, connective tissue disorders (i.e. rheumatoid arthritis, systemic lupus erythromatous), collagenopathies (i.e. Marfarn syndrome) and primary

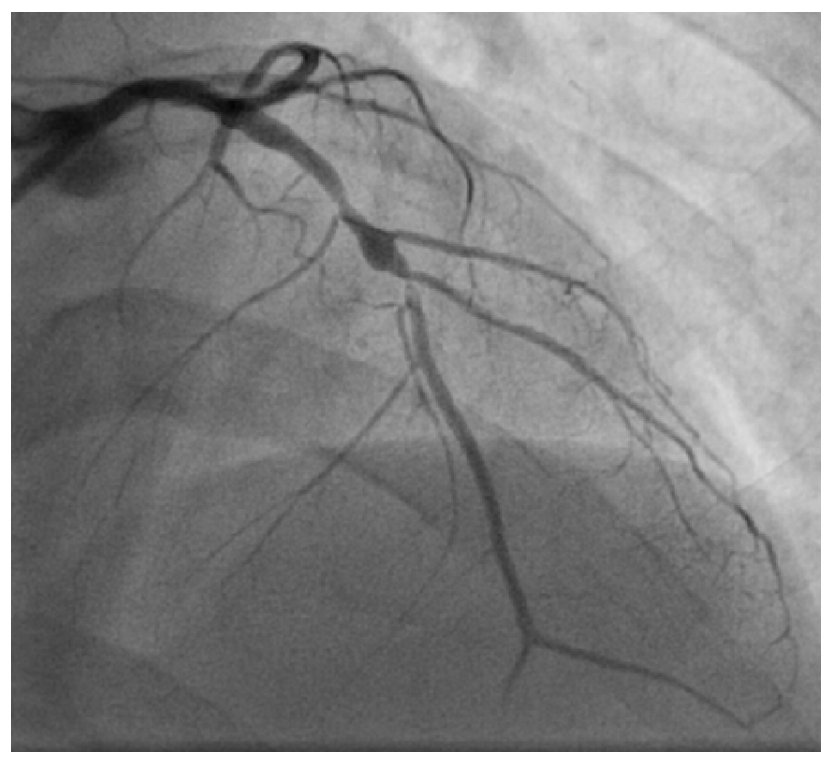

Figure 1. Coronary angiogram revealed single vessel disease with $70 \%$ occlusion in proximal LAD, $90 \%$ occlusion in mid$\mathrm{LAD}$ as well as ectasia in proximal-mid junction of LAD. 
Table 1. Classification of coronary artery ectasia as per Markis classification system.

\begin{tabular}{cc}
\hline Type of Ectasia & Definition \\
\hline Type 1 & Diffuse ectasia of two or three vessels \\
Type 2 & Diffuse ectasia in one vessel and localized disease in another \\
Type 3 & Diffuse ectasia in one vessel only \\
Type 4 & Localized and segmental involvement \\
\hline
\end{tabular}

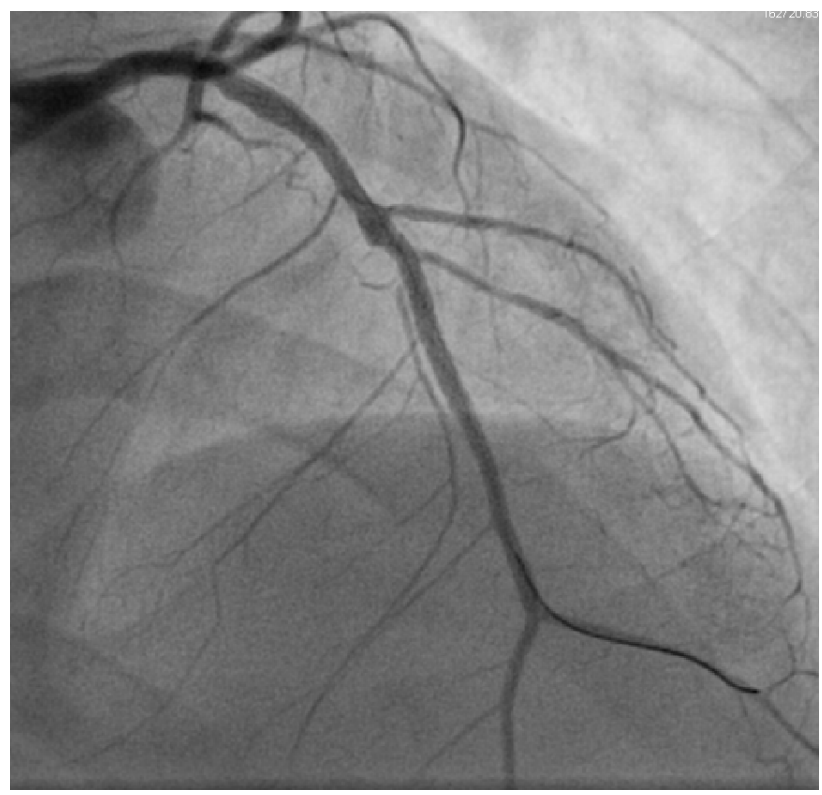

Figure 2. Post-procedural coronary angiogram showed well-placed stent in proximal-mid LAD.

hyperaldosteronism [5] [6]. In our case also, patient had ectasia in proximal-mid of LAD as well as stenosis in proximal (70\%) and mid (90\%) of LAD.

CAE may remain asymptomatic and diagnosed incidentally but in some cases, the patient experienced myocardial infraction due to recurrent thrombus formation [9]. Similarly, Zografos et al., in their retrospective study, found that myocardial infraction was more common in patients with diffuse ectasia [2]. They also explained that intracoronary thrombus formation and embolization (as a result of slow flow due to ectasia) lead to frequent myocardial infractionin patients with ectasia.

There is no consensus for the management of CAE [5]. The treatment approach ranges from medical observation to revascularization depending upon the clinical manifestation of the patient. Ozcan et al. has reported caseseries. In the two cases of this case-series, the patient was followed medically for aneurysm in left main coronary artery as there was no stenosis or flow-limitation [10]. Similarly, Wells et al. has reported a case of elderly patient who was successfully treated with coronary artery bypass grafting (CABG) for calcified lesion of LAD but the aneurysm was left alone and the six-month follow-up showed no cardiovascular complication [11].

PCI of the stenosis adjacent to ectasia is challenging with regard to optimal stent sizing, misplacement, embolization of the stent, early stent thrombosis or restenosis and it requires caution for adequate stent expansion and wall apposition [4] [6] [12]. Stefanadis et al. has reported superior outcomes covered stents for sealing of coronary aneurysm as compared to bare metal stent [12]. Drug-eluting stent reduces the rate of re-stenosis but due to larger vessel diameter in ectatic coronary artery disease, it is generally not used in this clinical condition [6] [13]. However, Rha et al. has reported successful implantation of two drug-eluting stents parallel to each other in ectatic LAD artery [13]. The author also recommended the clinician should consider parallel stenting of the drugeluting stents as a new intervention strategy. 
We have reported favorable outcomes of deployment of drug eluting stent in CAE associated with artherosclerosis. We had deployed drug-eluting stent after considering age as well as co-morbid condition (type-II diabetes mellitus) of the patient.

\section{References}

[1] Swaye, P.S., Fisher, L.D., Litwin, P., Vignola, P.A., Judkins, M.P., et al. (1983) Aneurysmal Coronary Artery Disease. Circulation, 67, 134-138. http://dx.doi.org/10.1161/01.CIR.67.1.134

[2] Zografos, T.A., Korovesis, S., Giazitzoglou, E., Kokladi, M., Venetsanakos, I., et al. (2013) Clinical and Angiographic Characteristics of Patients with Coronary Artery Ectasia. International Journal of Cardiology, 167, 1536-1541. http://dx.doi.org/10.1016/j.ijcard.2012.04.098

[3] Markis, J.E., Joffe, C.D., Cohn, P.F., Feen, D.J., Herman, M.V., et al. (1976) Clinical Significance of Coronary Arterial Ectasia. The American Journal of Cardiology, 37, 217-222. http://dx.doi.org/10.1016/0002-9149(76)90315-5

[4] Mavrogeni, S. (2010) Coronary Artery Ectasia: From Diagnosis to Treatment. Hellenic Journal of Cardiology, 51, 158163.

[5] Ozcan, O.U. and Gulec, S. (2013) Coronary Artery Ectasia. Cor et Vasa, 55, e242-e247. http://dx.doi.org/10.1016/j.crvasa.2013.01.003

[6] Lin, C.-T., Chen, C.-W., Lin, T.-K. and Lin, C.-L. (2008) Coronary Artery Ectasia. Tzu Chi Medical Journal, 20, 270274. http://dx.doi.org/10.1016/S1016-3190(08)60049-X

[7] Manginas, A. and Cokkinos, D.V. (2006) Coronary Artery Ectasias: Imaging, Functional Assessment and Clinical Implications. European Heart Journal, 27, 1026-1031. http://dx.doi.org/10.1093/eurheartj/ehi725

[8] Befeler, B., Aranda, J.M., Embi, A., Mullin, F.L., El-Sherif, N., et al. (1977) Coronary Artery Aneurysms: Study of Their Etiology, Clinical Course and Effect on Left Ventricular Function and Prognosis. The American Journal of Medicine, 62, 597-607. http://dx.doi.org/10.1016/0002-9343(77)90423-5

[9] Chen, C.-H., Lin, C.-T. and Lin, T.-K. (2010) Coronary Artery Ectasia Presenting with Recurrent Inferior Wall Myocardial Infarction. Tzu Chi Medical Journal, 22, 119-122. http://dx.doi.org/10.1016/S1016-3190(10)60053-5

[10] Ozcan, O., Canbay, A., Vural, M., Diker, E. and Aydogdu, S. (2007) Left Main Coronary Artery Aneurysm: Report of Three Cases. Cardiovascular Revascularization Medicine, 8, 278-280. http://dx.doi.org/10.1016/j.carrev.2007.02.003

[11] Wells, T., Peebles, C. and Gray, H. (2008) Giant Left Anterior Descending Coronary Artery Aneurysm. International Journal of Cardiology, 126, e27-e28. http://dx.doi.org/10.1016/j.ijcard.2007.01.009

[12] Stefanadis, C., Toutouzas, K., Tsiamis, E. and Toutouzas, P. (2002) New Stent Design for Autologous Venous GraftCovered Stent Preparation: First Human Application for Sealing of a Coronary Aneurysm. Catheterization and Cardiovascular Interventions, 55, 222-227. http://dx.doi.org/10.1002/ccd.10087

[13] Rha, S.W., Wani, S.P. and Oh, D.J. (2007) Parallel Stenting Using Two Sirolimus-Eluting Stents in an Ectatic Coronary Artery Stenosis. Heart, 93, 976. http://dx.doi.org/10.1136/hrt.2006.099739 
Scientific Research Publishing (SCIRP) is one of the largest Open Access journal publishers. It is currently publishing more than 200 open access, online, peer-reviewed journals covering a wide range of academic disciplines. SCIRP serves the worldwide academic communities and contributes to the progress and application of science with its publication.

Other selected journals from SCIRP are listed as below. Submit your manuscript to us via either submit@scirp.org or Online Submission Portal.
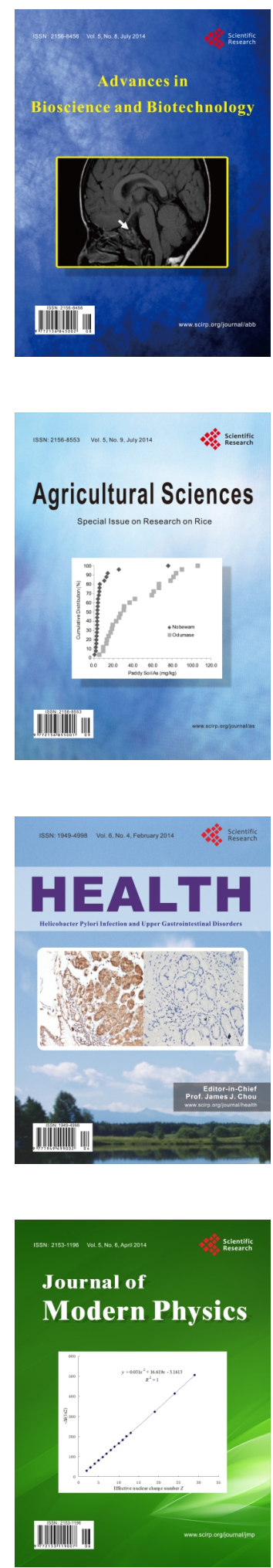
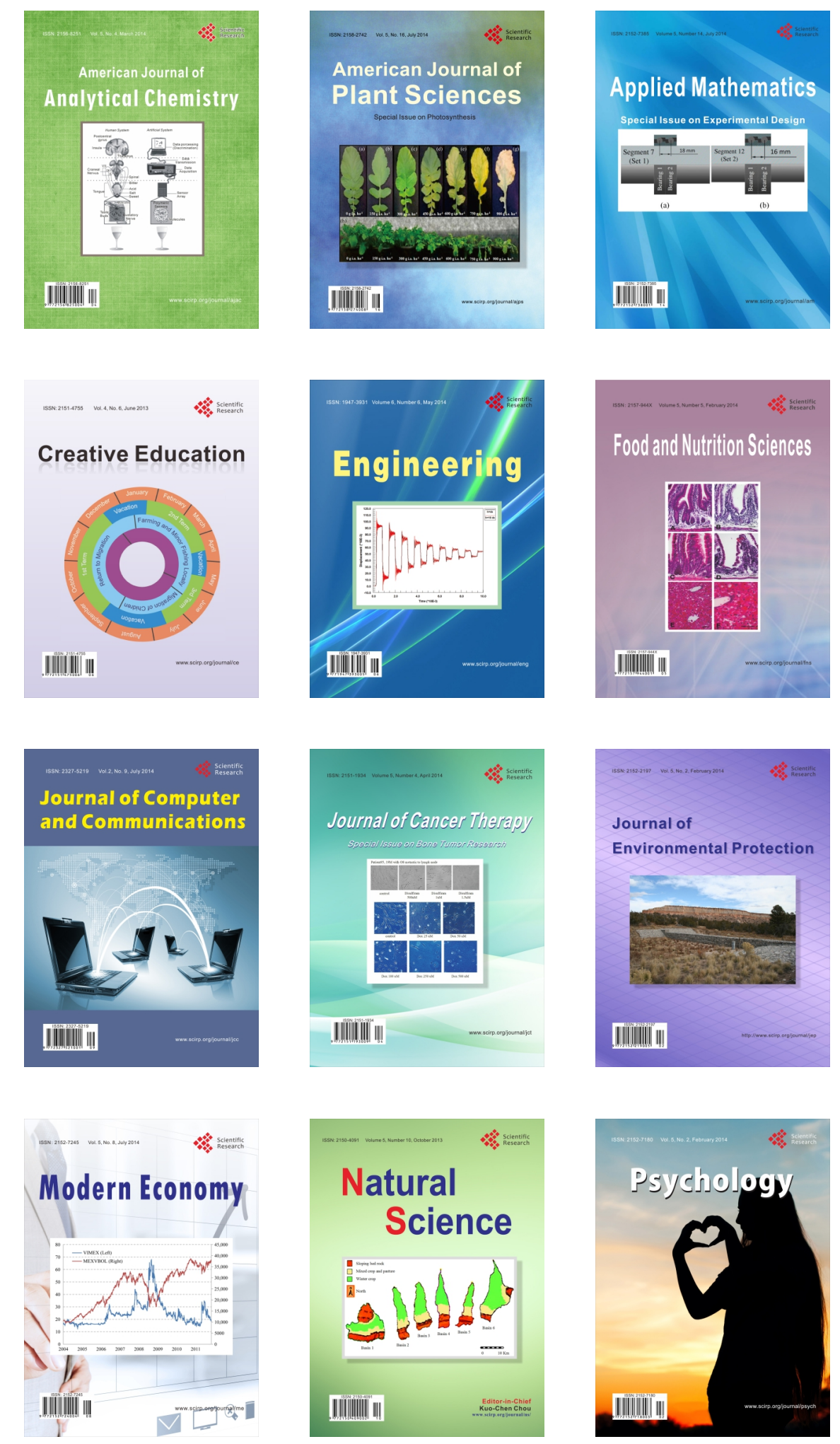